\title{
Effectiveness of a Brief Physician Counselling Session on Improving Smoking Behaviour in the Workplace
}

\author{
Yung Wen Han ${ }^{1 *}$, Mohazmi Mohammad², Su May Liew²
}

\begin{abstract}
Background: Brief physician counselling has been shown to be effective in improving smokers' behaviour. If the counselling sessions can be given at the workplace, this would benefit a larger number of smokers. This study aimed to determine the effectiveness of a ten-minute physician counseling session at the workplace in improving smoking behaviour. Materials and Methods: This prospective randomised control trial was conducted on smokers in a factory. A total of 163 participants were recruited and randomised into control and intervention groups using a table of random numbers. The intervention group received a ten-minute brief physician counselling session to quit smoking. Stages of smoking behaviour were measured in both groups using a translated and validated questionnaire at baseline, one month and three months post intervention. Results: There was a significant improvement in smoking behaviour at one-month post intervention $(p=0.024$, intention to treat analysis; $O R=2.525 ; C I=1.109-5.747)$. This was not significant at three-month post intervention ( $p=0.946$, intention to treat analysis; $O R=1.026 ; 95 \% \mathrm{CI}=0.486-2.168)$. Conclusions: A session of brief physician counselling was effective in improving smokers' behaviour at workplace, but the effect was not sustained.
\end{abstract}

Keywords: Physician counselling - smoking behaviour - transtheoretical model - workplace - randomised control trial.

Asian Pac J Cancer Prev, 15 (17), 7287-7290

\section{Introduction}

Smoking cessation is the most prioritized intervention in reducing premature death and preventable morbidity and disability from non-communicable diseases stated from UN High-Level Meeting (Beaglehole et al., 2011). In Malaysia, the prevalence of smokers is 3.6 million and is expected to rise to 4.6 million by 2025 (Mahayiddin et al., 2003). Nearly half of men are smokers, and the majority of them are between the ages of 25 and 44 years (GATS: Malaysia 2011).

Meta-analysis showed that a simple, brief physician counselling increased the likelihood of quit smoking by 66\% (Stead LF et al., 2008). This is a cost effective way of encouraging smokers to quit. However, this counselling is often only offered opportunistically to those consulting for other illnesses. The majority of smokers in Malaysia are in the productive age group and are unlikely to visit a physician regularly. In fact, this had been a neglected group of smokers for most smoking cessation intervention.

The workplace, for example a factory where most of its workers are smokers and male, is a good place to target our intervention. The interaction between smokers and non-smokers, the acceptance and denial of smoking habits at the workplace play important roles in successful smoking cessation (Nishiura et al., 2009). It is reasonable to choose a workplace that can represent the majority of the smokers' working environment to test the efficacy of the intervention. It also serves as a good platform for us to explore possible difficulties to smoking cessation among smokers working in this environment.

The objective of this study is to determine the effectiveness of this intervention when given at the workplace, in this case, in a factory, as an initial step to changing the behaviour of smokers at the workplace.

\section{Materials and Methods}

This was a prospective randomised control trial conducted in the workplace clinic at a car manufacturing plant in Selangor, Malaysia. A total sample size of 148 was calculated using the quit rate $(22 \%)$ from a previous study (Yasin et al., 2011) using a confidence interval of $95 \%$ and power of $80 \%$. Estimating a drop out rate of $10 \%$ (Jayakrishnan et al., 2011), the targeted sample size was 163 .

Ethical approval was obtained from University Malaya ethical board. This study had been registered retrospectively under Australian New Zealand Clinical Trials Registry (ANZCTR) with registration number ACTRN12613000870752.

Exclusion criteria were 1) illiteracy, and 2) those

${ }^{1}$ Department of Primary Care, Faculty of Medicine, University Teknologi Mara, Selayang, ${ }^{2}$ Department of Primary Care Medicine, Faculty of Medicine, University of Malaya, Kuala Lumpur, Malaysia *For correspondence: yungwen7@gmail.com 
who already quit smoking. Randomisation was carried out according to a sequence obtained from a table of random numbers. Allocation was concealed from both participants and researcher until informed consent was taken. A baseline questionnaire on demographic data and on stages of smoking behaviour was filled by participants in both groups (Figure 1). The translated and validated version of the Stages of Change Questionnaire Short Form in Malay was used (Yasin et al., 2011).

The intervention was a ten minutes counselling session from the researcher, who is a certified quit smoking instructor. The counselling was based on the 5A's and 5R's model (Fiore et al., 2008). These were individualised session conducted face-to-face according to the participants' stages of smoking behaviour.

Those participants in the pre-contemplation stage were advised regarding the harms of tobacco and advised to quit in a clear manner. Those participants in the contemplation stage were reinforced on the harms of tobacco and given methods of quit smoking, possible withdrawal symptoms were explained. For those in the preparation group, the methods of quit smoking were discussed, a quit date was decided, and possible withdrawal symptoms were explained. All relapsers were discussed regarding their difficulties during last quit attempt, and advices were given to help them to overcome it.

Both control and intervention groups received a list of quit smoking clinics addresses and contact numbers. The same questionnaire was used to reassess participants' stages at one month and three months post intervention. The self reported quit rates were used to measure quit rate at three months post intervention.

Statistical analysis were done using SPSS version 20.0. The changes in stages of smoking behaviour were analysed at one month and three months post intervention. A forward change in stages of behaviour was analysed as

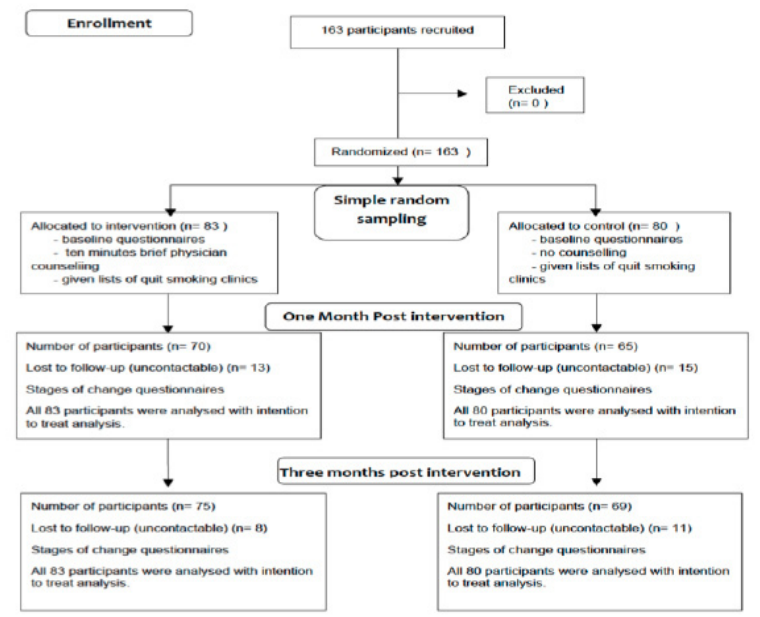

Figure 1. Flow Chart of Methodology

improvement; and no change or backward change in stages of behaviour was analysed as no improvement, regardless of the number of steps of forward or backward. The participants who were lost to follow up were categorized as no improvement. Chi-Square test was used to study the association between categorical variables (e.g. between change of stages of smoking behaviour and the control or intervention groups), and $p$ value of $<0.05$ was taken as statistical significant.

\section{Results}

The response rate was very good with all invited and eligible smokers agreeing to participate in this study. All 163 participants were male smokers. The majority were under 40 years of age. (Table 1) Most of the participants started smoking at an early age, and for more than 10 years. Mean number of cigarettes smoked per day was 11.5 \pm 6.8 . Three quarters of the participants had attempted to quit at

Table 1. Demographic Characteristics of All the Participants

\begin{tabular}{|c|c|c|c|c|c|}
\hline \multicolumn{2}{|l|}{ Characteristics } & $\begin{array}{l}\text { Controls } \\
\mathrm{N}(\%) \\
\mathrm{N}=80\end{array}$ & $\begin{array}{c}\text { Intervention } \\
\begin{array}{c}\mathrm{N}(\%) \\
\mathrm{N}=83\end{array}\end{array}$ & $\begin{array}{c}\text { Total } \\
\mathrm{N}(\%) \\
\mathrm{N}=163\end{array}$ & $\mathrm{p}$ Value \\
\hline \multicolumn{2}{|c|}{ Mean age \pm SD (years) } & $34.5 \pm 9.0$ & $34.5 \pm 8.5$ & $34.5 \pm 8.7$ & $0.983 *$ \\
\hline \multirow[t]{4}{*}{ Education level } & Primary & $1(1.3)$ & $0(0.0)$ & $1(0.6)$ & 0.516 \\
\hline & Secondary & $68(85.0)$ & $68(81.9)$ & $136(83.4)$ & \\
\hline & Diploma & $9(11.3)$ & $10(12.0)$ & $19(11.7)$ & \\
\hline & Tertiary & $2(2.5)$ & $5(6.0)$ & $7(4.3)$ & \\
\hline \multirow[t]{3}{*}{ Marital status } & Single & $27(33.8)$ & $24(28.9)$ & $51(31.3)$ & 0.510 \\
\hline & Married & $53(66.2)$ & $58(69.9)$ & $111(68.1)$ & \\
\hline & Widow/Widower & $0(0.0)$ & $1(1.2)$ & $1(0.6)$ & \\
\hline \multicolumn{2}{|c|}{ Mean age started smoking $\pm \mathrm{SD}$ (years) } & $17.0 \pm 3.5$ & $17.5 \pm 3.0$ & $17.3 \pm 3.3$ & $0.455^{*}$ \\
\hline \multicolumn{2}{|c|}{ Mean years of smoking $\pm \mathrm{SD}$} & $17.4 \pm 8.3$ & $16.9 \pm 7.8$ & $17.2 \pm 8.0$ & $0.693^{*}$ \\
\hline \multicolumn{2}{|c|}{ Mean number of cigarettes per day \pm SD } & $11.0 \pm 6.3$ & $11.9 \pm 7.2$ & $11.5 \pm 6.8$ & $0.370 *$ \\
\hline \multirow[t]{2}{*}{ Quit attempts } & Yes & $56(70.0)$ & $66(79.5)$ & $122(74.8)$ & 0.116 \\
\hline & No & $24(30.0)$ & $17(20.5)$ & $41(25.2)$ & \\
\hline \multirow[t]{2}{*}{ Parents smoking } & Yes & $48(60.0)$ & $55(66.3)$ & $103(63.2)$ & 0.407 \\
\hline & No & $32(40.0)$ & $28(33.7)$ & $60(36.8)$ & \\
\hline \multirow[t]{3}{*}{ Stages of Change } & Pre-contemplation & $29(36.3)$ & 37 ( 44.6) & $66(40.5)$ & 0.556 \\
\hline & Contemplation & $18(22.5)$ & $16(19.3)$ & $34(20.9)$ & \\
\hline & Preparation & $33(41.2)$ & $30(36.1)$ & $63(38.7)$ & \\
\hline
\end{tabular}

*Foot note=there are five stages of change, but individuals in the action and maintainence stage were excluded. $* *$-analysis by t-test; all others were analysed by Chisquare test 
Table 2. Improvement in Stages of Smokers' Behaviour One Month and Three Months Post Intervention

\begin{tabular}{|c|c|c|c|}
\hline & $\begin{array}{l}\text { Improve- } \\
\text { ment }\end{array}$ & $\begin{array}{c}\text { No Improve- } \\
\text { ment* }\end{array}$ & $\begin{array}{r}\text { P value, Odds } \\
\text { Ratio }(95 \% \text { CIl })\end{array}$ \\
\hline \multicolumn{4}{|c|}{ One month post intervention } \\
\hline Control & $10(12.5)$ & $70(87.5)$ & $\begin{array}{r}0.024 ; 2.525 \\
(1.109-5.747)\end{array}$ \\
\hline Intervention & $22(26.5)$ & $61(73.5)$ & \\
\hline \multicolumn{4}{|c|}{ Three months post intervention } \\
\hline Control & $17(21.2)$ & $63(78.8)$ & $\begin{array}{r}0.946 ; 1.026 \\
(0.486-2.168)\end{array}$ \\
\hline Intervention & $18(21.7)$ & $65(78.3)$ & \\
\hline
\end{tabular}

*-No Improvement-includes missing data as intention to treat. Missing data in control group (one month post intervention-15 participants, three months post intervention-11 participants); intervention group (one month post intervention-11 participants, three months post intervention- 8 participants)

least once previously. Majority of the participants came from family with parent/parents smoking.

There were $66(40.5 \%)$ participants in the precontemplation stage, $34(20.9 \%)$ in the contemplation stage, and $63(38.7 \%)$ in the preparation stage at baseline. Demographic data and smoking history were not significantly different in both groups.

There was a statistically significant change in smoking behaviour at one-month post intervention $(\mathrm{p}=0.024$, intention to treat analysis; $\mathrm{OR}=2.525$; $\mathrm{CI}=1.109-5.747$ ). This was not sustainable at three months post intervention $(\mathrm{p}=0.946$, intention to treat analysis; $\mathrm{OR}=1.026 ; 95 \%$ $\mathrm{CI}=0.486-2.168)$. (Table 2)

The self-reported quit rate at three months in the control and intervention group were $8.8 \%$ and $10.8 \%$ respectively. (Results not shown in table) However, it was not statistically significant (Pearson Chi-Square $\mathrm{p}=0.104$ ) between the control and intervention group.

\section{Discussion}

The key findings of this study are: 1) that a brief physician counseling session given at the work place is effective in improving smoking behaviour at one month, and 2) this is not sustainable at three months post intervention.

The counseling was effective because it was delivered face-to-face and advice was tailored according to the smoker's smoking behaviour. This method of counseling was chosen in this study due to its wide acceptance, ready availability in the form of clinical practice guidelines in Malaysia (Mahayiddin et al., 2003) and proven efficacy in assisting smoking cessation (Stead et al., 2008). This counseling method can be easily incorporated into any workplace without incurring much additional cost, and changes in the pre-existing working environment. Although combining behavioural counseling with pharmacotherapy is proven to have better smoking cessation rate (Stead and Lancaster, 2012), but the additional cost of pharmacotherapy needs to be taken into consideration. Furthermore, pharmacotherapy is not readily accessible to many smoking cessation clinics in Malaysia.

The added advantage of brief smoking cessation counselling is that it is equally effective when delivered by other trained professionals such as pharmacists (Sinclair et al., 2004), dentists (Oberoi et al., 2014), medical social workers (Pimple et al., 2012) and medical students (Kadowaki et al., 2004). This provides an opportunity to involve a large readily available human resource in providing smoking cessation counseling.

This study showed that although this intervention is effective, its effects were not sustainable. This is similar to the findings of other randomised controlled trial done in this region (Kim et al., 2005). This could be due to the baseline characteristic of the smokers, and lack of nonsmoking policy in the working environment in this study.

In terms of baseline characteristics, most of the smokers came from family with parent/parents smoking, and they started smoking at a young age $(17.3 \pm 3.3$ years old) in this study. Similarly, regional studies (Jayakrishnan et al 2013; Zhu et al 2010) also showed that mean age started smoking were $15 \pm 8.28$ and $20 \pm 5$ years old respectively. This means that the smokers are more likely to have longer years of exposure to nicotine, and higher tendency to have nicotine addiction. This made smoking cessation challenging.

Furthermore, this study showed that $40.5 \%$ smokers were in pre-contemplation phase of smoking behaviour, which means that they were not ready to change. Smokers in this phase were less likely to seek help from any quit smoking facilities. This finding is consistent with lower participation rate in younger smokers in smoking cessation programs held in local clinics (Kim et al., 2013), making them the neglected group of smokers for any smoking cessation intervention. Hence it is important to bring the intervention to workplace rather than waiting passively for the smokers to come to clinics. As the previous study had showed, the younger the smokers quit, the longer the life expectancy gained (Doll et al., 2004).

There was also a lack of non-smoking policy in this work place. There were no observed specific smoking areas for smokers; non-smokers and smokers who were attempting to quit were equally exposed to environmental tobacco smoke in the working environment. This directly made smokers who attempting to quit harder to quit, and those non-smokers were exposed to the harmful effects of environmental tobacco smoke. As shown in previous study (Nishiura et al., 2009), the smoking norms and prevalence of smokers in workplace could affect the outcome of smoking cessation.

In order to improve sustainability of the effect of this intervention, more follow up counseling sessions could be arranged. Other studies from various parts of the world (Pierterse et al., 2001; Hilberink et al., 2005; Jayakrishnan et al., 2013; Kim et al., 2013) had showed better outcome with more counseling sessions, either in the form of telephone consultation, face-to-face interview, or group counseling. From the feedback of the participants in this study, similar brief counseling sessions either in the form of telephone consultation or face-to-face interviews were preferred because of the limited time off they get during working hours (limited to $15 \mathrm{~min}$ in the morning, $45 \mathrm{~min}$ lunch break, and another $15 \mathrm{~min}$ at tea break). Some participants, especially the relapsers, had suggested for pharmacotherapy to be given immediately upon request to shorten the counseling sessions. 
The strength of this study is that it addressed a different group of smokers compared to other studies. The counseling was done at work place clinic (in a factory) compared to general physician clinics. The participants came to the clinic for reasons other than illnesses were recruited. They were larger percentage of participants in pre-contemplation phase compared to previous studies suggested that less motivated smokers were also captured.

The limitations of this study include: (1) There may be contamination between the intervention and the control groups as they were both recruited in the same workplace. However, this unavoidable due to the design of the study. (2) The counseling session was only conducted once, we were not sure if multiple sessions of counseling might improve the outcome in this setting. (3) Self-reported smoking cessation was used as the measurement of quit rate at three months, this might over estimate the quit rate. Although there was study that showed that there were no significant differences between the quit rate measured by exhaled carbon monoxide levels or self reported (Wong et al., 2012).

In the future, more sessions of counseling is recommended to improve the smoking behaviour at the workplace. A non-smoking working environment and quit smoking counseling clinics should be supported by the employer in order to improve attendance and progress of smoking behaviour at this workplace.

In, conclusion, A session of brief physician counselling was effective in changing smokers' behaviour at workplace, but the effect was not sustainable.

\section{Acknowledgements}

This research was funded by the Postgraduate Research Fund (PPP) of University of Malaya.(P0097/2012) We would also like to thank all the participants from Perusahaan Otomobil Nasional Sdn Bhd, Malaysia for joining this research, and all the staff in the clinic for helping and providing an appropriate place for the counseling sessions.

\section{References}

Beaglehole R, Bonita R, Horton R, et al (2011). Priority actions for the non-communicable disease crisis. The Lancet, $\mathbf{3 7 7}$, 1438-47.

Doll R, Peto R, Boreham J, et al (2004) Mortality in relation to smoking: 50 years' observations on male British doctors. $B M J, 328,1519$.

Fiore MC, Jaen CR, Baker TB, et al (2009) Treating tobacco use and dependence: 2008 update: quick reference guide for clinicians. rockville, MD: U.S. department of health and human services. Public Health Service.

Hilberink SR, Jacobs JE, Bottema Ben J. A. M., et al. (2005). Smoking cessation in patients with COPD in daily general practice (SMOCC): Six months' results. Prev Med, 41, 822-7.

Jayakrishnan R, Mathew A, Uutela A, et al (2011). A community based smoking cessation intervention trial for rural Kerala, India. Asian Pac J Cancer Prev, 12, 3191-5.

Jayakrishnan R, Mathew A, Uutela A, et al (2013). Multiple approaches and participation rate for a community based smoing cessation intervention trial in rural Kerala, India.
Asian Pac J Cancer Prev, 14, 2891-6.

Kadowaki T, Okamura T, Funakoshi T, et al (2004). Effectiveness of annual interventions for smoking cessation in an occupational setting in Japan. Environ Health Prev Med, 9, 161-4.

Kim H, Oh JK, Lim MK, et al (2013). The national "smoking cessation clinics" program in the republic of Korea: socioeconomic status and age matter. Asia Pac J Cancer Prev, 14, 6919-24.

Kim JR, Lee MS, Hwang JY, et al (2005). Efficacy of a smoking cessation intervention using the AHCPR guideline tailored for Koreans: a randomized controlled trial. Health Promotion International. 20, 51-9.

Mahayiddin A, Mazlan M, Abu Bakar S, et al (2003). Clinical practice guideline: treatment of tobacco use and dependence. Putrajaya: Ministry of Health, Malaysia

Nishiura C, Narai R, Ohguri T, et al (2009). The effect of smoking prevalence at worksites on individual cessation behavior. $J$ Occup Health, 51, 48-56.

Oberoi SS, Sharma G, Nagpal A, et al (2014). Tobacco cessation in India: how can oral health professionals contribute? Asia Pac J Cancer Prev, 15, 2383-91.

Pieterse ME, Seydel ER, DeVries H, et al (2001). Effectiveness of a minimal contact smoking cessation program for dutch general practitioners: a randomized controlled trial. Prev Med, 32, 182-90.

Pimple S, Pednekar M, Majmudar P, et al (2012). An integrated approach to worksite tobacco use prevention and oral cancer screening among factory workers in mumbai, India. Asia Pac J Cancer Prev, 13, 527-32.

Sinclair HK, Bond CM, Stead LF (2004). Community pharmacy personnel interventions for smoking cessation. Cochrane Database Syst Rev, 1, 003698.

Stead LF, Bergson G, Lancaster T (2008). Physician advice for smoking cessation. Cochrane Database Syst Rev, 2, 000165.

Stead LF, Lancaster T (2012) Combined pharmacotherapy and behavioural interventions for smoking cessation. Cochrane Database Syst Rev, 10, 008286.

Tobacco use. Global Adult Tobacco Survey: Malaysia Report 2011, Ministry of health, government of Malaysia.

Yasin SM, Taib KM, Zaki RA (2011). Reliability and construct validity of the bahasa Malaysia version of transtheoretical model (TTM) questionnaire for smoking cessation and relapse among Malaysian adult smokers. Asian Pac J Cancer Prev, 12, 1439-43.

Yasin SM, Retneswari M, Foong MM, et al (2011). Smokers can quit regardless of motivation stage in a worksite smoking cessation programme in Malaysia. Asian Pac J Cancer Prev, 12, 2193-8.

Zhu WH, Yang L, Jiang CQ, et al (2010). Characteristics of smokers and predictors of quitting in a smoking cessation clinic in Guangzhou, China. J Public Health. 32, 267-76. 